\title{
Evaluation of respiratory effects in miners and millers exposed to talc free of asbestos and silica
}

\author{
D H WEGMAN, J M PETERS, ${ }^{*}$ MARYANNE G BOUNDY, $\dagger$ AND T J SMITH
}

From the Occupational Health Program, Department of Physiology, and the Department of Environmental Health Sciences, Havard School of Public Health, Boston, Massachusetts 02115, USA

ABSTRACT Miners and millers of talc ore, free from asbestos and silica, were examined for respiratory effects. A study of 116 subjects included the modified British Medical Research Council respiratory symptom questionnaire, simple spirometry, chest radiography, and limited examination of the chest. A one-year follow-up evaluation was performed on 103 subjects. Of the 12 subjects whose chest radiographs showed small round or irregular opacities (perfusion 1/0 or greater), five had never smoked cigarettes. Pulmonary function values at the time of the initial study were less than predicted and the rates of loss of FEV, and FVC greater than expected. These differences were in part attributed to cigarette smoking but were greater than predicted from that source alone. There was evidence of an exposure effect after adjusting for cigarette smoking and we conclude that these workers have been affected by their exposures. No clear interaction between smoking and exposure could be identified. Populations such as this will need to be studied for longer periods to determine what current dust levels are safe.

Studies on the health effects of exposure to talc ${ }^{1-12}$ suggest that it causes both a pneumoconiosis and chronic respiratory impairment. These investigations are complicated by the fact that exposure to talc is often accompanied by exposure to silica, asbestos, and other minerals. Since Vermont talc deposits contain very small amounts of these contaminants, the workers employed in Vermont talc mines and mills represent a population exposed only to industrial grade talc. ${ }^{13-15} \mathrm{~A}$ study was undertaken to examine both the work environment of Vermont mines and mills and the respiratory state of the employees.

The research was designed to determine the level and type of exposure to talc, to assess the extent of respiratory disease in the working population, and

${ }^{*}$ Present address: University of Southern California, Department of Preventive Medicine, Los Angeles, CA 90033, USA.

†Present address: Setauket, NY11733, USA.

Supported by: National Institute of Environmental Health Sciences, grant No ES00002 and the National Insitute for Occupational Safety and Health, grant No 210-75-0005.

Requests for reprints to: David $\mathrm{H}$ Wegman, MD, Occupational Health Program, Havard School of Public Health, 665 Huntington Avenue, Boston, Massachusetts 02115.

Received 14 July 1981

Accepted 3 April 1982 to identify a relationship (if any) between exposure and effect.

\section{Methods}

POPULATION AND MEASUREMENT OF HEALTH EFFECTS

The potential population consisted of 174 miners and millers currently employed by three talc companies in Vermont. Only $142(82 \%)$ were examined (32 workers were absent or refused to participate) of whom 116 were 25 or older; data are presented for this latter group.

Questionnaire-A medical history was obtained from each subject, including medical history pertinent to the respiratory system, and a modification of the British Medical Research Council Questionnaire for respiratory symptoms was completed. Detailed lifetime smoking histories were taken from each individual. A complete occupational history was obtained from each company, including, where known, history of work before employment in the talc industry.

Pulmonary function tests-At least three satisfactory forced expirations after maximum inspiration were recorded for each worker on a Stead Wells (Collins) 10-litre spirometer with a kymograph speed of $3.2 \mathrm{~cm} / \mathrm{s}$. From these tracings, the forced vital capacity (FVC) and forced expiratory volume 
in one second $\left(\mathrm{FEV}_{1}\right)$ were derived by standard methods. The mean of the two larger satisfactory trials with no larger than $5 \%$ variation was corrected to BTPS. All 116 met this criterion. Maximal mid-expiratory flow (MMEF) was taken from the tracing with the largest sum of $\mathrm{FEV}_{1}$ and FVC. No appropriate control group was available for study at the time this investigation was carried out. For this reason the method of analysis selected was to compare the observed pulmonary function values to predicted ones from a standard population. Regional differences in pulmonary function have been examined in another study ${ }^{16}$ and have been found to be not significant. Measured (observed) FVC, FEV $_{1}$, and MMEF were compared with expected values derived from the prediction equations of Knudson et al. ${ }^{17}$ Knudson used a pneumotachograph rather than the modified Stead Wells spirometer used in this study. To achieve equivalency, therefore, the flow derived predicted FEV was multiplied by the factor 1.035 as reported by Knudson. Since there are no well-established predicted equations for MMEF, Knudson's calculated MMEFs were also selected for comparison with the measured MMEFs. These are all presented as the ratio of observed over expected multiplied by 100 .

One year later, 127 of the original $142(89 \%)$ were restudied. Three were dead or seriously ill, nine were no longer employed, and three refused to participate. Of the 127 restudied subjects, 103 were 25 or older in the first year of the study. Decrements over the study year were determined by subtracting the second test value from the first. Since the follow-up studies were done between 10 and 14 months after the original study, the decrements were adjusted to a 12-month year. Decrements are presented as positive values.

Chest radiography-Posterioranterior chest radiographs were taken in full inspiration in a mobile unit that contained a $200 \mathrm{MA}, 125 \mathrm{KV}$ photo-timed unit that takes $14^{\prime \prime}$ by $17^{\prime \prime}(35 \mathrm{~cm}$ by 43 $\mathrm{cm}$ ) radiographs at a standard distance of six feet $(1.82 \mathrm{~m})$. Of the 116 workers older than 25 , only 100 volunteered for chest radiographs. The radiographs were read independently according to the ILO/UICC classification by two readers who had been trained in this system. When there were disagreements a third reader was added to resolve the differences. Population means for age, years employed, years smoked, and pulmonary function (FVC\% predicted and MMEF\% predicted) were compared between the 116 total study group and the 100 with adequate posterioranterior radiographs. There was no difference at the $p<0.10$ level.

\section{EXPOSURE MEASUREMENTS AND ESTIMATES}

Three sources of information were available for estimating the long-term dust exposures of the subjects.

(1) Periodic survey data collected by the Vermont Division of Occupational Health (VT-DOH) during 1938-71. Limitations of this source are that the samples were collected for less than a full working day, only a few individuals were sampled during each visit, and dust measurements were made by midget impinger.

(2) Our 1975-6 measurements consisted of respirable mass samples taken at the lapel over a full shift done in all three companies. The three companies were visited in summer and winter. A total of 312 personal (lapel) respirable mass samples (118 in mines and 194 in mills) were taken with a mass respirable sampler at a flow rate of $1.71 / \mathrm{m}$. The first stage of this two-stage sampler consisted of a $10-\mathrm{mm}$ nylon cyclone. The second stage was a polyvinyl chloride membrane-filter with a stainless steel backing plate. All filters were dried in a vacuum dessicator for a minimum of $\mathbf{4 8}$ hours before being reweighed. Half the samples were analysed for free silica content by infrared spectrophotometry ${ }^{18}$ and $20 \%$ by $x$-ray diffraction. Fifty-seven parallel samples were taken for fibre determinations using 0.8 $\mu \mathrm{m}$ membrane filters using phase contrast microscopy at $437 \times$ magnification and on the $0.4 \mu \mathrm{m}$ filters by scanning electron microscopy at $5000 \times$ magnification.

To determine a factor to convert impinger counts to respirable mass concentrations a small series of samples was collected in 1975-6 using the impinger and respirable mass samplers concurrently. The conversion factor was based on samples from work areas and jobs that had not changed.

(3) Historical information (1930-75) from each company was developed into descriptions of work practices and facilities associated with each job category. Exposure was estimated for each job. It was assumed that exposures stayed the same if there were no changes in the job or the facilities. This assumption was verified by the VT-DOH data in several cases. Where significant changes had occurred-for example, the introduction of wet drilling-past measurements were used to estimate the approximate magnitude of the change. The dates for these changes in each company were used to describe average exposure levels in a job or work area as a function of time. In some cases the changes were not sharply demarcated by dates or no measurements were available to indicate the magnitude of the changes in exposures. When this happened, anecdotal information on the differences in exposure reported by the old managers and employees 
was used to estimate changes. There was no way to assess the accuracy of this approach for filling in missing data. The oldest exposure estimates were probably the least quantitative.

Based on the estimates of the dust reduction due to engineering changes, jobs in each company were given a factor to adjust current exposure to past exposure. Current exposure for muckers, scrapers, or slushers was multiplied by 10 to estimate exposures before 1971 for two companies and before 1974 for the third. Current exposure for all miners were multiplied by 2 to estimate exposures before 1971 in the same two companies and before 1974 for the third. Milling jobs were not adjusted for the second or third companies but were multiplied by 5 for exposures before 1970 in the first.

Bulk samples from representative milling and mining operations were collected from each location. These specimens were analysed by $x$-ray diffraction for their mineral constituents and by atomic absorption for trace metals. Aliquots of the bulk samples were sent to NIOSH and the company for comparison.

Job exposure assignments-Two different estimates of exposure were made. The first was an estimate of the geometric mean exposure for each job in each mill or mine which was received by an employee during the year of study ("current exposure"). The second was a lifetime dust exposure estimate ("talc years"). For this measurement an individual's work history was divided into years in each job. Current exposure for each job was adjusted where appropriate by the factor estimating prior exposures.

Then an index was developed as follows:

$$
\text { Talc years } \underset{i=1}{\sum_{i=1}^{n}}\left(K_{j} \times T_{j}\right)
$$

Where

$\mathbf{n}=$ number of times a man changed jobs

$\mathrm{j}=$ jobs

$\mathrm{T}=$ time spent in each job

$\mathbf{K}=$ dust concentration, either current or adjusted, depending on time period during which job was worked.

\section{Results}

The cross-sectional data for pulmonary function (table 1) show that mean observed/predicted FVC (FVC\%) for this population is not significantly different from 100, while observed/predicted $\mathrm{FEV}_{1}$ (FEV\%) and observed/predicted MMEF (MMEF\%) are significantly reduced. Both years smoked and pack years produce the expected effect
Table 1 Cohort of talc miners and millers (1975-6): basic statistics

\begin{tabular}{|c|c|c|c|c|}
\hline & No & Mean & $S D$ & $p^{*}$ \\
\hline $\begin{array}{l}\text { Age (y) } \\
\text { Height (cm) } \\
\text { Years smoked } \\
\text { Years employed } \\
\text { FVC (l) } \\
\% \text { Predicted FVC } \\
\text { FEV (l) } \\
\% \text { Predicted FEV } \\
\text { MMEF (1/s) } \\
\% \text { Predicted MMEF } \\
\triangle \text { FVC (1) } \\
\triangle \text { FEV }_{1}(1)\end{array}$ & $\begin{array}{l}116 \\
116 \\
116 \\
116 \\
116 \\
116 \\
116 \\
116 \\
116 \\
\\
103 \\
103\end{array}$ & $\begin{array}{c}40 \cdot 7 \\
173 \cdot 9 \\
17 \cdot 5 \\
8 \cdot 5 \\
4 \cdot 74 \\
98 \cdot 0 \\
3 \cdot 61 \\
92 \cdot 6 \\
3 \cdot 16 \\
66 \cdot 2 \\
0.052 \\
0.062\end{array}$ & $\begin{array}{c}11 \cdot 0 \\
6 \cdot 4 \\
13 \cdot 7 \\
7 \cdot 6 \\
0 \cdot 90 \\
13 \cdot 2 \\
0 \cdot 86 \\
16 \cdot 6 \\
1 \cdot 37 \\
26 \cdot 3 \\
0 \cdot 305 \\
0 \cdot 218\end{array}$ & $\begin{array}{l}>0.10 \\
<0.001 \\
<0.001\end{array}$ \\
\hline
\end{tabular}

${ }^{*} t$ test for difference from $100 \%$.

on pulmonary function: decrease in $\mathrm{FEV} \%$ and MMEF\% and little or no effect on FVC\% (table 2).

When exposure to talc was considered, years of employment and talc years were significantly associated with decreasing $\mathrm{FEV}_{1} / \mathrm{FVC}$ and MMEF\% (table 3) but not with FVC\% or FEV\%. No effects are apparent on FVC.

Since the amount and duration of smoking are correlated with amount and duration of exposure to talc, we stratified the talc exposure groups by smoking history (table 4) to look for independent effects. If talc (at these levels) has an independent effect on pulmonary function, then individuals with high talc years will tend to have lower pulmonary function than those with low talc years in each smoking stratum. This was the case for FEV/FVC and for MMEF\%. To examine the exposure effects adjusted for smoking history a two-way analysis of variance was computed using the grouped variables from table 4: exposure ( $<6.25$ talc years, $\geqslant 6.25$ talc years) and smoking history (non-smoker, current smokers $<20$ years, current smokers $>20$ years, ex-smokers $<20$ years, ex-smokers $>20$ years). The analysis showed a significant smoking effect as expected for all but FVC\%. The same analysis showed, after adjustment for cigarette smoking, a difference for exposure between high and low talc year groups for FVC $\%$ of $0.5 \%(p=0.84)$, for FEV\% of $4.5 \%(p=$ $0 \cdot 18)$, for FEV/FVC of $3.6 \%(p=0.03)$, and for MMEF\% of $8.9 \%(p=0.04)$. The difference favoured the low exposure group in every instance, although the difference was significant only for FEV/FVC and MMEF\%. A separate analysis of variance was computed to test for an interaction between smoking and exposure. There was a suggestion of such an interaction for FEV/FVC and MMEF\% but neither interaction achieved statistical significance.

Chest radiographs-Radiographic investigation showed a $43 \%$ prevalence of any chest $x$-ray 
Table 2 Cohort of talc miners and millers (1975): pulmonary function by smoking variables

\begin{tabular}{|c|c|c|c|c|c|}
\hline Years smoked & No & $F E V \%$ & FVC\% & $\frac{F E V}{F V C} \times 100$ & $M M E F$ \\
\hline $\begin{array}{l}\text { Never } \\
<10 \\
10-19 \\
20-29 \\
\geqslant 30 \\
\text { Total } \\
\text { F } \\
\text { p }\end{array}$ & $\begin{array}{r}26 \\
14 \\
28 \\
21 \\
27 \\
116\end{array}$ & $\begin{array}{c}99.3 \\
101.0 \\
94.3 \\
85.6 \\
85.6 \\
92.6 \\
4.682 \\
<0.01\end{array}$ & $\begin{array}{c}100.9 \\
100.0 \\
97.7 \\
95.2 \\
96.6 \\
98.0 \\
0.661 \\
>0.50\end{array}$ & $\begin{array}{c}79 \\
82 \\
78 \\
72 \\
70 \\
76 \\
7.885 \\
<0.01\end{array}$ & $\begin{array}{l}79.2 \\
86.5 \\
71 \cdot 8 \\
51 \cdot 6 \\
47 \cdot 9 \\
66 \cdot 2 \\
12.383 \\
<0.01\end{array}$ \\
\hline $\begin{array}{l}\text { Pack years } \\
0 \\
1-19 \\
20-60 \\
>60 \\
\text { Total } \\
\text { F } \\
\text { p }\end{array}$ & $\begin{array}{r}26 \\
29 \\
33 \\
28 \\
116\end{array}$ & $\begin{array}{c}99.3 \\
98.0 \\
87.2 \\
87.3 \\
92.6 \\
4.944 \\
<0.01\end{array}$ & $\begin{array}{c}100.9 \\
99.2 \\
96.4 \\
96.0 \\
98.0 \\
0.882 \\
0.45\end{array}$ & $\begin{array}{c}79 \\
80 \\
72 \\
72 \\
76 \\
6.423 \\
<0.01\end{array}$ & $\begin{array}{l}79.2 \\
79.2 \\
56.5 \\
51 \cdot 5 \\
66.2 \\
11.181 \\
<0.01\end{array}$ \\
\hline
\end{tabular}

Table 3 Cohort of talc miners and millers (1975): pulmonary function by exposure variables

\begin{tabular}{|c|c|c|c|c|c|c|c|}
\hline Talc years & No & FEV\% & FVC\% & $\frac{F E V}{F V C} \times 100$ & $M M E F \%$ & No & $R V \%$ \\
\hline $\begin{array}{l}<1 \\
1-6 \cdot 24 \\
6 \cdot 25-12 \cdot 4 \\
12 \cdot 5-18 \cdot 6 \\
\geqslant 18 \cdot 7 \\
\text { Total } \\
\text { F } \\
\text { p }\end{array}$ & $\begin{array}{c}12 \\
39 \\
25 \\
16 \\
23 \\
115^{*}\end{array}$ & $\begin{array}{c}102.3 \\
94.3 \\
91.9 \\
87.7 \\
88.8 \\
92.6 \\
2.449 \\
0.05\end{array}$ & $\begin{array}{c}101.5 \\
97.7 \\
99.9 \\
94.1 \\
97.3 \\
98 \cdot 0 \\
0.880 \\
0.48\end{array}$ & $\begin{array}{c}79 \\
82 \\
78 \\
72 \\
70 \\
76 \\
7.885 \\
<0.01\end{array}$ & $\begin{array}{c}85 \cdot 3 \\
70.5 \\
62.3 \\
59.5 \\
57.7 \\
66.2 \\
3.837 \\
<0.01\end{array}$ & $\begin{array}{r}6 \\
32 \\
21 \\
12 \\
17 \\
88\end{array}$ & $\begin{array}{l}23.8 \\
21.2 \\
25.8 \\
26.3 \\
29.1 \\
25.2 \\
0.582 \\
>0.50\end{array}$ \\
\hline $\begin{array}{l}\text { Years worked } \\
<5 \\
5-9 \\
10-19 \\
\geqslant 20 \\
\text { Total } \\
\text { F } \\
\text { p }\end{array}$ & $\begin{array}{c}39 \\
43 \\
19 \\
15 \\
115^{*}\end{array}$ & $\begin{array}{l}97 \cdot 0 \\
92 \cdot 2 \\
90 \cdot 4 \\
85 \cdot 5 \\
92 \cdot 6 \\
1.968 \\
0 \cdot 12\end{array}$ & $\begin{array}{l}98 \cdot 5 \\
98 \cdot 0 \\
97.8 \\
96 \cdot 8 \\
98 \cdot 0 \\
0.071 \\
0.50\end{array}$ & $\begin{array}{l}0.79 \\
0.76 \\
0.74 \\
0.68 \\
0.76 \\
6.119 \\
<0.01\end{array}$ & $\begin{array}{c}76.7 \\
64 \cdot 1 \\
61 \cdot 2 \\
50.9 \\
66.2 \\
4.169 \\
<0.01\end{array}$ & $\begin{array}{l}27 \\
33 \\
18 \\
10 \\
88\end{array}$ & $\begin{array}{l}18.4 \\
24.6 \\
27 \cdot 1 \\
37.8 \\
27.0 \\
7.333 \\
<0.001\end{array}$ \\
\hline
\end{tabular}

${ }^{*}$ Years worked was not recorded for one individual.

Table 4 Cohort of talc miners and millers (1975): comparison of exposure and smoking variables

\begin{tabular}{|c|c|c|c|c|c|c|}
\hline & Talc years & $\mathrm{No}$ & FVC\% & FEV \% & $F E V / F V C$ & MMEF\% \\
\hline Non-smokers & $\begin{array}{l}6 \cdot 25 \\
6 \cdot 25\end{array}$ & $\begin{array}{l}16 \\
10\end{array}$ & $\begin{array}{r}98 \cdot 9 \\
104 \cdot 0\end{array}$ & $\begin{array}{l}99.0 \\
99.8\end{array}$ & $\begin{array}{l}0.81 \\
0.77\end{array}$ & $\begin{array}{l}83.3 \\
72.6\end{array}$ \\
\hline $\begin{array}{l}\text { Current smokers } \\
<20 \\
\geqslant 20\end{array}$ & $\begin{array}{l}6 \cdot 25 \\
6 \cdot 25 \\
6 \cdot 25 \\
6 \cdot 25\end{array}$ & $\begin{array}{l}14 \\
13 \\
13 \\
22\end{array}$ & $\begin{array}{l}99 \cdot 2 \\
94 \cdot 7 \\
96 \cdot 7 \\
94 \cdot 4\end{array}$ & $\begin{array}{l}93.6 \\
94.5 \\
91.9 \\
81.9\end{array}$ & $\begin{array}{l}0.77 \\
0.81 \\
0.76 \\
0.69\end{array}$ & $\begin{array}{l}68 \cdot 5 \\
80 \cdot 1 \\
60 \cdot 4 \\
43 \cdot 1\end{array}$ \\
\hline $\begin{array}{l}\text { Ex-smokers } \\
<20 \\
\geqslant 20\end{array}$ & $\begin{array}{l}6 \cdot 25 \\
6 \cdot 25 \\
6 \cdot 25 \\
6 \cdot 25\end{array}$ & $\begin{array}{r}6 \\
9 \\
3 \\
10\end{array}$ & $\begin{array}{r}101 \cdot 3 \\
100 \cdot 7 \\
96 \cdot 3 \\
98 \cdot 5\end{array}$ & $\begin{array}{r}106 \cdot 6 \\
97 \cdot 2 \\
90 \cdot 8 \\
83 \cdot 9\end{array}$ & $\begin{array}{l}0.85 \\
0.77 \\
0.74 \\
0.67\end{array}$ & $\begin{array}{l}95 \cdot 4 \\
72 \cdot 0 \\
60 \cdot 6 \\
47 \cdot 2\end{array}$ \\
\hline
\end{tabular}


Table 5 Cohort of talc miners and millers (1975): smoking and exposure variables by $x$-ray examination

\begin{tabular}{|c|c|c|c|c|c|}
\hline$X$-ray abnormalities & No & Years smoked & Pack years & Talc years & Years employed \\
\hline $\begin{array}{l}\text { Small round opacities } \\
\text { Absent } \\
\text { Present }\end{array}$ & $\begin{array}{l}88 \\
12\end{array}$ & $\begin{array}{l}17 \cdot 3 \\
17 \cdot 3 \\
\text { NS }\end{array}$ & $\begin{array}{l}33 \cdot 0 \\
33 \cdot 9 \\
\text { NS }\end{array}$ & $\begin{array}{c}189.3 \\
528 \cdot 8 \\
0.003\end{array}$ & $\begin{array}{c}7.8 \\
15.5 \\
0.001\end{array}$ \\
\hline $\begin{array}{l}\text { Small irregular opacities } \\
\text { Absent } \\
\text { Present } \\
\mathrm{p}^{*}\end{array}$ & $\begin{array}{r}91 \\
9\end{array}$ & $\begin{array}{l}16 \cdot 8 \\
23 \cdot 2 \\
\text { NS }\end{array}$ & $\begin{array}{l}31 \cdot 2 \\
51 \cdot 8 \\
\text { NS }\end{array}$ & $\begin{array}{l}192.8 \\
607.0 \\
<0.001\end{array}$ & $\begin{array}{c}7.9 \\
17.3 \\
<0.001\end{array}$ \\
\hline
\end{tabular}

${ }^{*} t$ test for difference in mean values.

abnormality, but only a third of these abnormalities were diffuse parenchymal opacities or pleural abnormalities. Talc years was associated with both small rounded and irregular opacities while smoking was not. Five of the 12 subjects with small rounded opacities had never smoked cigarettes (table 5). Ten subjects had pleural abnormalities; four had blunting of the costophrenic angles bilaterally, four pleural plaques and diffuse pleural thickening, and in two the only pleural abnormality was an illdefined diaphragm. None of the radiographic changes reported in table 5 correlated with the pulmonary function results.

Longitudinal evaluations-Few longitudinal studies of pulmonary function in normal populations have been reported. Several of those which used water-filled spirometers report a range of expected annual decrements for FEV 1 of between 19 and 47 $\mathrm{ml} / \mathrm{y} \cdot{ }^{19-23}$ In heavy smokers the range is 25 to 51 $\mathrm{ml} / \mathrm{y}$. The average annual loss of pulmonary function in this study was raised for $\mathrm{FEV}_{1}(62 \mathrm{ml})$ but not significantly different from the values reported above. Table 6 presents exposure and pack year variables compared with annual decrement. Although pack years and years employed show a trend with annual decrement of $\mathrm{FEV}_{1}$, current exposure and talc years do not. Neither the trend present for change in FEV and years employed nor pack years was significant.

Clinical symptoms of respiratory disease-On cross-sectional evaluation, those individuals with a variety of respiratory symptoms appeared to have impaired lung function. Both pack-years and years exposed to talc showed a weak correlation with symptoms of cough and phlegm. When the symptoms as reported in 1975 were compared with the change in lung function over the subsequent year, no particular pattern emerged.

Environmental evaluation-The details of the environmental sampling are presented in another paper. ${ }^{24}$ In summary, the talc was found to be essentially free from silica and asbestos. Exposure levels were found to be below $3.0 \mathrm{mg} / \mathrm{m}^{3}$ of respirable dust
Table 6 Cohort of talc miners and millers (1975 and 1976): change in pulmonary function by smoking and exposure

\begin{tabular}{|c|c|c|c|}
\hline & No & $\triangle F E V$ & $\triangle F V C$ \\
\hline \multicolumn{4}{|l|}{ Pack years } \\
\hline 0 & 23 & 0.027 & 0.015 \\
\hline$<20$ & 25 & 0.042 & 0.082 \\
\hline $20-60$ & 31 & 0.076 & 0.084 \\
\hline$>60$ & 24 & 0.096 & 0.007 \\
\hline Total & 103 & 0.062 & 0.052 \\
\hline \multicolumn{4}{|l|}{ Talc years } \\
\hline 0 & 12 & 0.119 & $0 \cdot 017$ \\
\hline $1-6 \cdot 24$ & 36 & 0.063 & $0 \cdot 100$ \\
\hline $6 \cdot 25-12 \cdot 4$ & 20 & -0.003 & -0.031 \\
\hline $12 \cdot 5-18 \cdot 6$ & 13 & $0 \cdot 109$ & 0.071 \\
\hline$\geqslant 18.7$ & 22 & 0.059 & 0.055 \\
\hline Total & 103 & 0.062 & 0.052 \\
\hline \multicolumn{4}{|c|}{ Years employed } \\
\hline$<5$ & 35 & 0.050 & 0.094 \\
\hline $5-9$ & 39 & 0.043 & 0.020 \\
\hline $10-19$ & 17 & 0.074 & 0.020 \\
\hline$\geqslant 20$ & 12 & 0.136 & 0.076 \\
\hline Total & 103 & 0.062 & 0.052 \\
\hline \multicolumn{4}{|c|}{ Current exposure } \\
\hline 0 & 18 & 0.064 & 0.046 \\
\hline$<1.82$ & 24 & 0.082 & $0 \cdot 110$ \\
\hline $1 \cdot 82-2 \cdot 22$ & 42 & 0.066 & 0.021 \\
\hline$\geqslant 2 \cdot 23$ & 19 & 0.023 & 0.052 \\
\hline Total & 103 & 0.062 & 0.052 \\
\hline
\end{tabular}

and the geometric mean exposure for the population was $1.8 \mathrm{mg} / \mathrm{m}^{3}$ of respirable dust.

\section{Discussion}

Exposure to talc (free of asbestos and silica) has been suggested as a cause of obstructive pulmonary effects in smokers. ${ }^{1011}$ The results of the crosssectional portion of this study are consistent with this suggestion, but a clear confirmation was lacking. After adjusting for cigarette smoking the two-way analysis of variance did show an effect in the high talc years group but this was not significant. Exposure to talc was associated with small opacities on chest radiographs while smoking was not.

The medium cumulative dust level for the high exposure group was 13.8 talc years accumulated over a median of nine years. Thus the annual expo- 
sure for this group was about $1.5 \mathrm{mg} / \mathrm{m}^{3}$. Exposure effects of the magnitude reported here in association with this level of exposure could be medically significant after a full working life. Since the study group had worked only a quarter of a working life (median nine years) this suggests that the current threshhold limit value which is greater than $5 \mathrm{mg} / \mathrm{m}^{3}$ should be re-evaluated if the pulmonary function effects noted in cigarette smokers in this study are to be prevented.

The annual loss in $\mathrm{FEV}_{1}$ and FVC seen in the prospective portion of the study suggests that these workers are losing pulmonary function at a rate greater than expected. This loss, however, does not correlate with current levels of exposure to talc dust. Unfortunately, the follow-up interval is short and the overall range of exposures within this study $(0 \cdot 2$ to $3.0 \mathrm{mg} / \mathrm{m}^{3}$ ) may be too narrow to detect exposure-related effects with such a small study population.

Effects on pulmonary function in non-smokers was not associated with lifetime or current talc exposure after a relatively short average years employed ( 8.5 years). Longer follow-up is desirable before concluding there is no effect of talc on nonsmokers at this level of exposure.

\section{References}

' Dreessen WC, Dalla Valle JM. The effects of exposure to dust in two Georgia talc mills and mines. Public Health Reports 1935;50:131-43.

${ }^{2}$ Hogue WL, Mallette FS. A study of workers exposed to talc and other dusting compounds in the rubber industry. Journal of Industrial Hygiene and Toxicology 1949;31:359-64.

${ }^{3}$ Mann B, Deasy JB. Talc pneumoconiosis in the textile industry. Br Med J 1954;ii:1460-1.

4 Kipling MD, Bech AO. Talc pneumoconiosis. Transactions of the Association of Industrial Medical Officers 1960;10:85-93.

${ }^{5}$ Kleinfeld M, Messite J, Shapiro J, Kooyman O, Swencicki R. Lung function in talc workers. Arch Environ Health 1964;9:559-66.

${ }^{6}$ Kleinfeld M, Messite J, Kooyman O, Shapiro J. Pulmonary ventilatory function in talcosis of lung. Dis Chest 1964;46:592-8.
${ }^{7}$ Kleinfeld MD, Messite J, Shapiro J, Swencicki R. Effects of talc dust inhalation on lung function. Arch Environ Health 1965;10:431-7.

${ }^{8}$ Miller A, Teirstein AS, Bader ME, Bader RA, Selikoff IJ. Talc pneumoconiosis. Am J Med 1971;50:395-402.

' Kleinfeld M, Messite J, Langer AM. A study of workers exposed to asbestiform minerals in commercial talc manufacture. Environ Res 1973;6:132-43.

${ }^{10}$ Fine LJ, Peters JM, Burgess WA, DiBeradinis LJ. Studies of respiratory morbidity in rubber workers. Arch Environ Health 1976;31:195-200.

"Hildick-Smith GY. The biology of talc. $\mathrm{Br} J$ Ind Med 1976;33:217-29.

12 Gamble JF, Fellner W, Dimeo M. An epidemiologic study of a group of talc workers. Am Rev Respir Dis 1979;119:741-53.

${ }^{13}$ Jacobs EC. Talc and the talc deposits of Vermont. Ninth Report. Vermont State Geologists, 1914:382-429.

${ }_{14}$ Jacobs EC. The talc and verde antique deposits of Vermont. State Department of Vermont, Barre, VT: Vermont State Geologists, 1914:232-81.

is Weiss B, Boettner E. Commercial talc and talcosis. Arch Environ Health 1967;14:304-8.

${ }^{16}$ Musk AW, Peters JM, Wegman DH, Fine LJ. Pulmonary function in granite dust exposure: a four year follow-up. Am Rev Respir Dis 1977;115:769-76.

${ }^{17}$ Knudson RJ, Slatin RC, Lebowitz MD, Burrows B. The maximal expiratory flow-volume curve. Am Rev Respir Dis 1976;113:587-600.

18 Cares JW, Goldin AS, Lynch JJ, Burgess WA. The determination of quartz in airborne respirable granite dust by infrared spectrophotometry. Am Ind Hyg Assoc J 1973;34:298-305.

19 Ferris BG, Chen H, Puleo S, Murphy RLH. Chronic non-specific repiratory disease in Berlin, New Hampshire 1967-1973. A further follow-up study. Am Rev Respir Dis 1976;113:475-82.

${ }^{20}$ Ferris BG, Puleo S, Chen $\mathrm{H}$. Mortality and morbidity in a pulp and a paper mill in the United States: a ten-year follow-up. $\mathrm{Br}$ $J$ Ind Med 1979;36:127-34.

${ }^{21}$ Berry C, McKerrow C, Molyneux M, Tobleson J. A study of the acute and chronic changes in ventilatory capacity of workers in Lancashire cotton mills. Br J Ind Med 1973;30:25-34.

${ }^{22}$ Kauffman F, Drovert I, Lellouch J, Brille D. Twelve years spirometric changes among Paris area workers. Int J Epidemiol 1979;8:201-12.

${ }^{23}$ Van der Lende R, Kok T, Reig P, Quanjer P, Schouten J, Orie N. Decreases in VC and FEV, with time: indicators for effects of smoking and air pollution. Bull Eur Physiopathol Respir 1981;17:775-92.

24. Boundy MG, Gold K, Martin KP, Burgess WA, Dement JM. Occupational exposures to non-asbestiform talc in Vermont. Dusts and disease. In: Lemen R, Dement JM. Proceedings of the Conference on Occupational Exposures to Fibrous and Particulate Dust and Their Extension into the Environment. Park Forest South Il: Pathotox Publishers, Inc, 1979. 